
JNM
J Neurogastroenterol Motil, Vol. 22 No. 4 October, 2016
pISSN: 2093-0879 elSSN: 2093-0887
http://dx.doi.org/10.5056/jnm16019

\title{
Esophageal Acid Clearance During Random Swallowing Is Faster in Patients with Barrett's Esophagus Than in Healthy Controls
}

\author{
Christian Lottrup, ${ }^{1,2,3}$ Anne L Krarup, ${ }^{1,3}$ Hans Gregersen, ${ }^{4 *}$ Per Ejstrud, ${ }^{5}$ and Asbjørn M Drewes ${ }^{1,2,6}$ \\ ${ }^{1}$ Mech-Sense, Department of Gastroenterology and Hepatology, Aalborg University Hospital, Aalborg, Denmark; ${ }^{2}$ Department of Clinical \\ Medicine, Aarhus University, Aarhus, Denmark; ${ }^{3}$ Department of Medicine, Vendsyssel Hospital, Hjørring, Denmark; ${ }^{4}$ GIOME, Department of \\ Surgery, Prince of Wales Hospital, Chinese University of Hong Kong, Shatin, Hong Kong SAR; ${ }^{5}$ Department of Surgery, Aalborg University \\ Hospital, Aalborg, Denmark; and ${ }^{6}$ Department of Clinical Medicine, Aalborg University, Aalborg; Denmark
}

\section{Background/Aims}

Impaired esophageal acid clearance may be a contributing factor in the pathogenesis of Barrett's esophagus. However, few studies have measured acid clearance as such in these patients. In this explorative, cross-sectional study, we aimed to compare esophageal acid clearance and swallowing rate in patients with Barrett's esophagus to that in healthy controls.

\section{Methods}

A total of 26 patients with histology-confirmed Barrett's esophagus and 12 healthy controls underwent (1) upper endoscopy, (2) an acid clearance test using a pH-impedance probe under controlled conditions including controlled and random swallowing, and (3) an ambulatory pH-impedance measurement.

\section{Results}

Compared with controls and when swallowing randomly, patients cleared acid $46 \%$ faster $(P=0.008)$. Furthermore, patients swallowed $60 \%$ more frequently (mean swallows/minute: $1.90 \pm 0.74$ vs $1.19 \pm 0.58 ; P=0.005$ ), and acid clearance time decreased with greater random swallowing rate $(P<0.001)$. Swallowing rate increased with lower distal esophageal baseline impedance $(P=0.014)$. Ambulatory acid exposure was greater in patients $(P=0.033)$, but clearance times assessed from the ambulatory pHmeasurement and acid clearance test were not correlated (all $P>0.3$ ).

\section{Conclusions}

More frequent swallowing and thus faster acid clearance in Barrett's esophagus may constitute a protective reflex due to impaired mucosal integrity and possibly acid hypersensitivity. Despite these reinforced mechanisms, acid clearance ability seems to be overthrown by repeated, retrograde acid reflux, thus resulting in increased esophageal acid exposure and consequently mucosal changes.

(J Neurogastroenterol Motil 2016;22:630-642)

\section{Key Words}

Acid clearance; Barrett esophagus; Deglutition; Esophageal pH monitoring; Gastroesophageal reflux

Received: January 27, 2016 Revised: May 9, 2016 Accepted: May 18, 2016

(a) This is an Open Access article distributed under the terms of the Creative Commons Attribution Non-Commercial License (http://creativecommons. org/licenses/by-nc/4.0) which permits unrestricted non-commercial use, distribution, and reproduction in any medium, provided the original work is properly cited.

*Correspondence: Hans Gregersen, PhD GIOME, Department of Surgery, Prince of Wales Hospital, Shatin, Hong Kong SAR Tel: +852-6921-8406, Fax: +852-2637-7974, E-mail: hag@giome.org 


\section{Introduction}

Barrett's esophagus (BE) is a premalignant condition in the esophagus characterized by replacement of squamous epithelium with columnar metaplasia. The prevalence of $\mathrm{BE}$ is $1-2 \%$, and its primary clinical relevance lies in the increased risk of esophageal adenocarcinoma. ${ }^{1}$ Because of the cancer risk and with considerable healthcare costs, international guidelines recommend surveillance of patients with $\mathrm{BE}^{2}$. The main factor underlying the development of $\mathrm{BE}$ is believed to be long-lasting gastroesophageal reflux disease. ${ }^{1}$ However, although the number and duration of reflux episodes are increased in $\mathrm{BE}^{3}$; these patients generally report few symptoms. ${ }^{4}$

Gastroesophageal reflux occurs when reflux contents reach the esophagus by surpassing the barrier at the esophagogastric junction. In this event, esophageal acid clearance in normal subjects usually restores a normal $\mathrm{pH}$ within 3-5 minutes. ${ }^{5}$ First, esophageal peristalsis clears the majority of the acid ("volume clearance"), ${ }^{6}$ and secondly bicarbonate-containing saliva neutralizes any remaining acid by "chemical clearance". ${ }^{7}$ Both of these mechanisms are believed to be activated and regulated via reflexes triggered by esophageal acidification and distension. ${ }^{8,9}$ When reflux content is not effectively cleared from the esophagus, the remaining acid can cause inflammatory damage to the esophageal mucosa. Over time, these changes can cause the development of erosive esophagitis (EE) or BE, dysplasia, and eventually cancer. ${ }^{10,11}$

A defect in either the afferent (eg, decreased sensitivity) or efferent part (eg, impaired peristalsis or saliva secretion) of the clearance reflex could impair esophageal acid clearance. With respect to the afferent part, this is supported by findings showing hyposensitivity to mechanical distension and heat stimulation in patients with BE. ${ }^{12,13}$ Relevant to the efferent part, impaired esophageal motility has been shown to be associated with $\mathrm{EE}$ and $\mathrm{BE} .{ }^{14}$ Several studies have also found increased acid exposure and prolonged acid clearance time in patients with $\mathrm{BE}$ using 24-hour esophageal $\mathrm{pH}$ impedance monitoring. ${ }^{3,15,16}$ Using impedance measurement, impaired activation of esophageal clearance was recently shown to be associated with dysplastic progression in $\mathrm{BE} .^{17}$ These findings indicate that acid clearance could be impaired in $\mathrm{BE}$ and possibly even be implicated in the development and progression of the condition.

However, since $\mathrm{pH}$-impedance measurements are done under non-standardized circumstances, confounding may arise because the volume, acidity, and extent of the individual reflux episodes are uncontrolled. ${ }^{18,19}$ In 1968 , Booth et $\mathrm{al}^{20}$ developed the esophageal acid clearance test, which takes many of these factors into account by standardizing volume and $\mathrm{pH}$ of the bolus to be cleared. Using this test, esophageal acid clearance has been shown to be impaired in patients with $\mathrm{EE}^{20-22}$ and hiatus hernia $(\mathrm{HH}){ }^{23,24}$ but results from the very limited number of studies in patients with $\mathrm{BE}$ disagree. ${ }^{25-27}$

We hypothesized that patients with $\mathrm{BE}$ have an impaired esophageal acid clearance compared with healthy controls. Using the standardized esophageal acid clearance test, we aimed to (1) measure esophageal acid clearance time (ACT) during several standardized physiologic conditions, (2) compare the swallowing rate in patients with $\mathrm{BE}$ and controls, and (3) compare acid clearance test assessment to that of conventional ambulatory $\mathrm{pH}$-impedance monitoring.

\section{Materials and Methods}

\section{Subject Selection}

As this was an explorative study and previous data were insufficient to allow this, no sample size calculation was done. However, from previous experience, a sample size of 30 patients with $\mathrm{BE}$ and 15 controls was chosen. A post hoc power calculation showed this to be sufficient with an estimated power of 0.85 for the acid clearance time measured during the random swallowing test. A 2:1 ratio was chosen, since the individual variability was expected to be greater in patients. Protocol and written information were approved by the North Denmark Region Committee on Health Research Ethics (project ID: N-20090008) and the study was undertaken in accordance with the Declaration of Helsinki. Patients with BE were recruited as previously described. ${ }^{28}$ The inclusion criteria for patients were age between 18 and 80 years and $\mathrm{BE}$ defined as intestinal metaplasia in biopsies from salmon-coloured esophageal mucosa $\geq 1 \mathrm{~cm}$ above the esophagogastric junction. ${ }^{29}$ An overview of the patient selection process is shown in Figure 1. Briefly, 937 patients were identified with $\mathrm{BE}$ from the pathology database at the Institute of Pathology, Aalborg University Hospital, Aalborg, Denmark. Fourteen healthy controls were recruited among persons, who had previously participated as healthy controls in experiments at our research center. Inclusion criteria for controls were age of 40 years or more, no reflux symptoms at the time of initial screening, and no medication known to affect esophageal sensation. Exclusion criteria were: (1) age below 18 or above 80 years, (2) body mass index (BMI) below 18.5 or above $35 \mathrm{~kg} / \mathrm{m}^{2}$, (3) concomitant disease compromising the subject's safety during participation in the study, (4) significant comorbidity such as alcohol abuse or psychiatric disorders, (5) prior esophageal surgery, and (6) subjects living more 
than $100 \mathrm{~km}$ from the hospital. For patients, further exclusion criteria were: (1) high-grade dysplasia or cancer in the initial histology report or (2) an endoscopy report stating either a Barrett segment length shorter than $\mathrm{C} 0 \mathrm{M} 2$ according to the Prague criteria ${ }^{30}$ or a clinical description clearly meaning the same. After exclusions, 89 patients were invited to participate. Of these 33 accepted, but three were later excluded or dropped out, leaving 30 to participate at visit 1. All subjects completed visit 1 with upper endoscopy as previously reported. ${ }^{28}$ Four patients were excluded between visit 1 and visit 2
(Fig. 1). Furthermore, one control withdrew consent and another was excluded due to endoscopic signs of EE. Hence, a total of 26 patients and 12 controls remained for inclusion in this part of the study. All clinical experiments in the protocol took place at Aalborg University Hospital, Aalborg, Denmark, from December 2011 to January 2013.

\section{Visit 1: Symptom Assessment and Endoscopy}

Figure 2A outlines the individual visits. Before inclusion, all

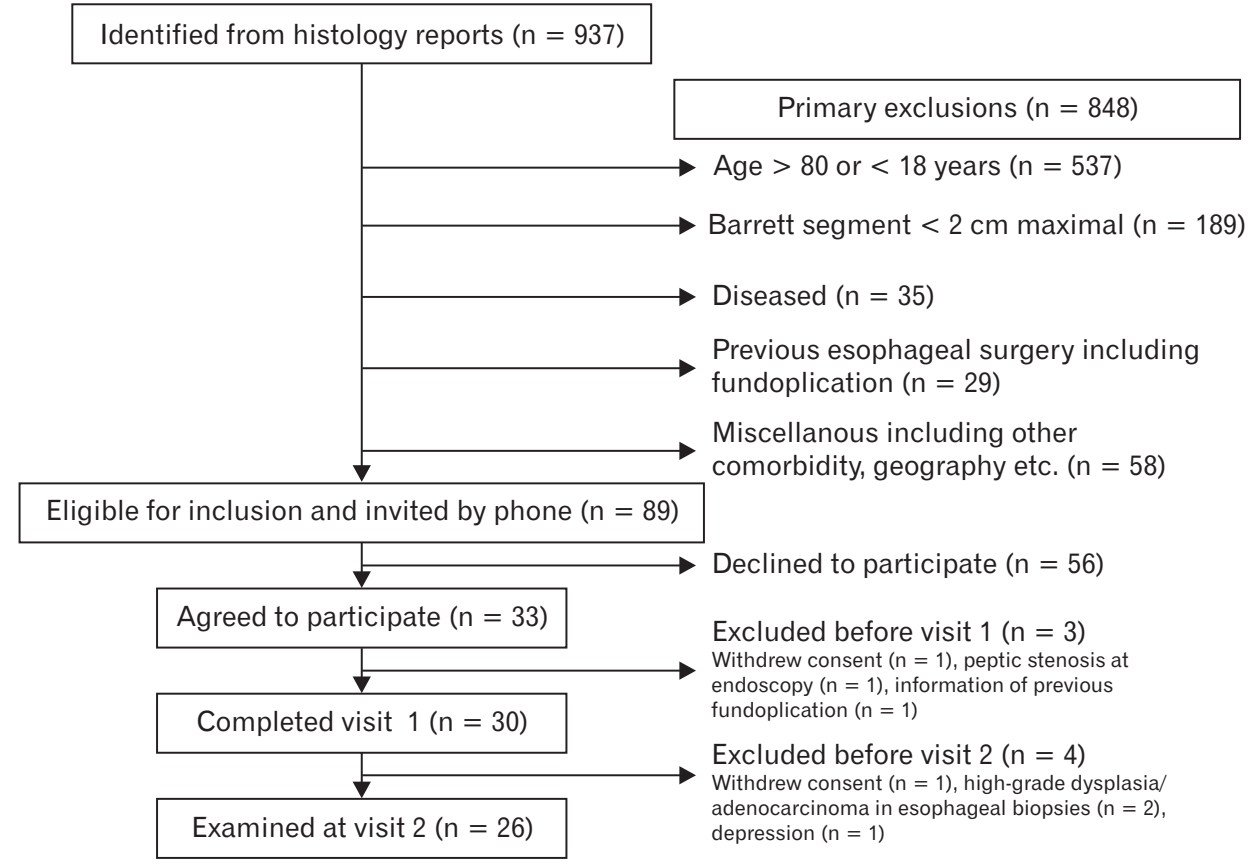

A

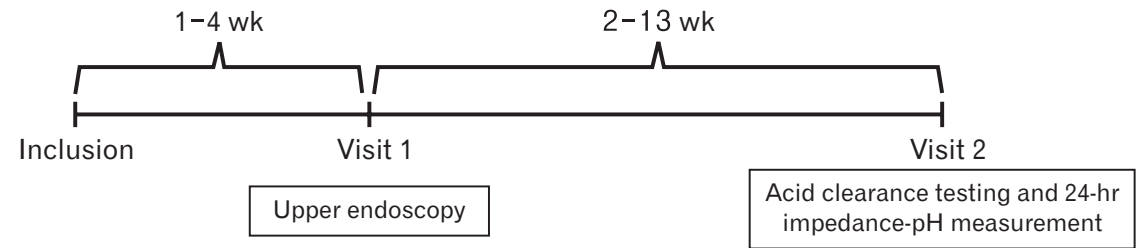

B

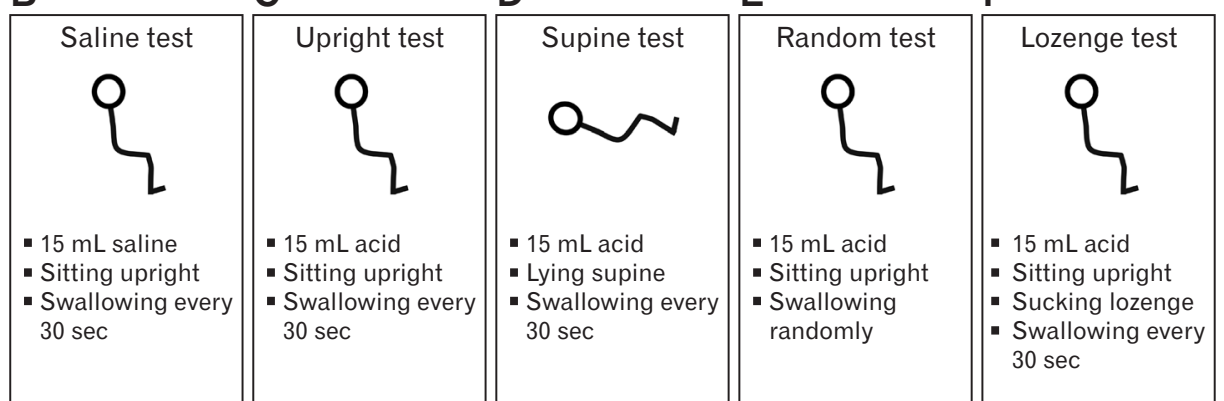

Figure 1. Selection of patients with Barrett's esophagus. A total of 26 patients participated in visit 2. See Figure 2 for details of the individual visits.
Figure 2. Protocol timeline and the 5 saline and acid clearance tests. (A) Flowchart showing individual visits; all subjects were to complete visit 1 and 2 within 13 weeks; (B) saline clearance test; (C) upright acid clearance test; (D) supine acid clearance test (head-of-bed elevated $30^{\circ}$ ); (E) random swallowing acid clearance test; and (F) lozenge acid clearance test (sucking a peppermint lozenge). 
subjects were informed about the study and gave their written consent to participate. At visit 1 , subjects scored frequency of gastrointestinal symptoms on a scale from 0 to 3 ( 0 : less than 1 day per month or not present at all; 1 : between 1 day per month and 1 day per week; 2: several days weekly; 3: daily). Grade 1 symptoms on this scale were allowed in controls due to the frequent reporting of reflux symptoms in the general population of this age. ${ }^{31}$ After an overnight fast and in all subjects (patients with $\mathrm{BE}$ and healthy controls), endoscopies were performed by 2 expert endoscopists using a high-definition endoscope. During the endoscopy, the location of the esophagogastric junction and the crural diaphragm measured from the incisor teeth along with Barrett segment length according to the Prague classification were assessed. ${ }^{30} \mathrm{~A}$ standard biopsybased urease test of Helicobacter pylori (ProntoDry; MIC France, Brignais, France) was performed. To balance sensitivity of the test against patient discomfort and protocol compliance, a 4-day pause in proton pump inhibitor (PPI) treatment before visit 1 was chosen. This time frame has been shown to be sufficient to avoid falsenegative results due to PPI treatment. ${ }^{32}$ Furthermore, one antrum as well as one corpus biopsy were taken from the stomach, since this increases sensitivity of the test compared with antral biopsies alone. ${ }^{33}$

\section{Visit 2: Acid Clearance Testing and Ambulatory pH Measurement}

\section{Acid clearance equipment}

A minimum of 2 weeks and a maximum of 13 weeks after visit 1,26 patients and 12 controls participated in visit 2 , before which PPI treatment was also paused for 4 days. Here, the standardized acid clearance test was performed using esophageal acid instillation as previously described ${ }^{7,34}$ with minor modifications. The K6011EI-0632 catheter (Unisensor, Attikon, Switzerland) was used, incorporating 6 impedance channels and 1 ISFET (ion sensitive field effect transistor) $\mathrm{pH}$ electrode for high accuracy. ${ }^{35}$ The catheter was modified by attaching a pediatric feeding tube for acid instillation. A digital data logger (Ohmega R; MMS B.V., Enschede, the Netherlands) was connected to the catheter. A computer showed $\mathrm{pH}$ and impedance live and recorded data. For recording and raw data analysis, MMS Database software (MMS B.V.) was used.

\section{Catheter calibration and placement}

The catheter was calibrated using buffers of $\mathrm{pH} 4.01$ and 7.01 as described by the manufacturer and then placed in the esophagus of the fasting subject. Preferably, subjects were intubated nasally, but some could not tolerate this and were intubated orally (Table 1).
For orally intubated subjects, the location of the lower esophageal sphincter (LES) was defined as the endoscopic distance from the incisor teeth to $1 \mathrm{~cm}$ above the proximal end of the gastric folds (Distance $\mathrm{LES}_{\mathrm{LE}, \text { oral }}$. ${ }^{36}$ For the subjects intubated nasally, the distance from the incisor teeth to the LES was calculated as [Distance LES, nasal $=$ Distance $\left._{\mathrm{LES}, \text { oral }}+4 \mathrm{~cm}\right] \cdot{ }^{36}$ Using these distances, the catheter was then placed with the $\mathrm{pH}$ electrode $5 \mathrm{~cm}$, the acid side channel opening $15 \mathrm{~cm}$, and the impedance channels $17,15,9,7,5$, and 3 $\mathrm{cm}$ above the LES.

\section{Acid clearance testing}

After adjustment to the catheter, mucosal baseline impedance was measured for 5 minutes. Then, 5 different acid clearance tests were performed (Fig. 2B-F). In all tests, isotonic saline $9 \mathrm{mg} / \mathrm{mL}$ or $0.1 \mathrm{~mol} / \mathrm{L}$ hydrochloric acid was instilled rapidly through the side channel using a syringe (duration: 5 seconds). During the tests, subjects swallowed either under controlled conditions every $30 \mathrm{sec}-$ onds (4 tests) or randomly depending on the subject's natural desire (1 test). From the time of instillation, recordings were made for 15 minutes. In the following order, tests included:

(1) Saline test: $15 \mathrm{~mL}$ saline and swallowing controlled

(2) Upright test: $15 \mathrm{~mL}$ acid in the upright position and swallowing controlled

(3) Supine test: $15 \mathrm{~mL}$ acid in the supine position and swallowing controlled

(4) Random test: $15 \mathrm{~mL}$ acid in the upright position and swallowing randomly

(5) Lozenge test: $15 \mathrm{~mL}$ acid in the upright position and swallowing controlled, but throughout the whole test sucking an oral peppermint lozenge (Polo; Nestlé UK Ltd, York, UK) to stimulate salivary secretion ${ }^{37}$

The saline test was used as placebo control of acid sensitivity, hence during all tests the subject was blinded to whether saline or acid was used. If $\mathrm{pH}$ was still below 4 after 15 minutes (900 seconds), the test was finished anyway and the ACT recorded as 900 seconds. Before the next test, it was ascertained that $\mathrm{pH}$ had risen above 4. During the lozenge test, the subject was given one or more new peppermint lozenge(s) when finishing the previous one to ensure constant saliva stimulation. During the entire experiment, the subject registered the following by pressing dedicated buttons on the data logger: planned swallows, random swallows, and the presence and duration of heartburn defined as a subjective sensation of burning in the retrosternal area. If heartburn was present, the subject was asked to score the maximal intensity on a $200 \mathrm{~mm}$ scale immediately after each test. ${ }^{38}$ 
Table 1. Clinical, Endoscopic, and $\mathrm{pH}$-impedance Parameters

\begin{tabular}{|c|c|c|c|}
\hline & Barrett & Controls & $P$-value \\
\hline \multicolumn{4}{|l|}{ Demography } \\
\hline Number of subjects & $25^{\mathrm{a}}$ & 12 & NA \\
\hline Age $(y r)$ & $63.9 \pm 7.3$ & $54.9 \pm 10.8$ & 0.005 \\
\hline Male:female ratio & $22: 3$ & $8: 4$ & NS \\
\hline Weight (kg) & $84.7 \pm 14.4$ & $74.5 \pm 10.4$ & 0.036 \\
\hline $\operatorname{BMI}\left(\mathrm{kg} / \mathrm{m}^{2}\right)$ & $27.5 \pm 3.9$ & $24.2 \pm 1.9$ & 0.009 \\
\hline Overweight (body mass index $>25 \mathrm{~kg} / \mathrm{m}^{2}$ ) & $16(64 \%)$ & $5(42 \%)$ & NS \\
\hline Present smoker & $7(28 \%)$ & $2(17 \%)$ & NS \\
\hline Alcohol consumption (drinks per wk) & $8.0 \pm 8.4$ & $5.4 \pm 4.3$ & NS \\
\hline Proton pump inhibitor use & $21(84 \%)$ & $0(0 \%)$ & $<0.001$ \\
\hline Diabetes mellitus type $2^{\mathrm{b}}$ & $3(12 \%)$ & $0(0 \%)$ & NS \\
\hline \multicolumn{4}{|l|}{ Symptoms } \\
\hline Heartburn & $11(44 \%)$ & $1(8 \%)$ & 0.058 \\
\hline Regurgitation & $9(36 \%)$ & $0(0 \%)$ & 0.018 \\
\hline Neither heartburn nor regurgitation & $12(48 \%)$ & $11(92 \%)$ & 0.013 \\
\hline \multicolumn{4}{|l|}{ Endoscopical data } \\
\hline Erosive esophagitis present ${ }^{c}$ & $8(32 \%)$ & NA & NA \\
\hline Barrett segment circular length ${ }^{\mathrm{d}, \mathrm{f}}(\mathrm{cm})$ & $4(1-18)$ & $\mathrm{NA}$ & NA \\
\hline Barrett segment maximal length ${ }^{\mathrm{d}, \mathrm{f}}(\mathrm{cm})$ & $6(2-19)$ & NA & NA \\
\hline Long-segment Barrett & $23(92 \%)$ & $0(0 \%)$ & $<0.001$ \\
\hline Hiatus hernia present & $19(76 \%)$ & $1(8 \%)$ & $<0.001$ \\
\hline Hiatus hernia length ${ }^{\mathrm{f}}(\mathrm{cm})$ & $3(0-6)$ & $0(0-3)$ & $<0.001$ \\
\hline Positive H. Pylori test (n) & $3(12 \%)$ & $1(8 \%)$ & NS \\
\hline \multicolumn{4}{|l|}{ Ambulatory $\mathrm{pH}$-impedance measurement } \\
\hline Accepted measurement & $21(84 \%)$ & $10(83 \%)$ & NS \\
\hline Valid data ${ }^{\mathrm{e}}$ & $18(72 \%)$ & $6(50 \%)$ & NS \\
\hline Duration $^{\mathrm{f}}(\mathrm{hr})$ & $24(19-26)$ & $24(15-31)$ & NS \\
\hline Total acid exposure time ${ }^{\mathrm{f}}(\%$ time $\mathrm{pH}<4)$ & $18(0-74)$ & $5(2-16)$ & 0.033 \\
\hline Upright acid exposure time $^{\mathrm{f}}(\%$ time $\mathrm{pH}<4)$ & $18(0-63)$ & $8(2-23)$ & NS \\
\hline Supine acid exposure time ${ }^{\mathrm{f}}(\%$ time $\mathrm{pH}<4)$ & $16(0-88)$ & $0(0-9)$ & 0.005 \\
\hline Total acid reflux episodes ${ }^{\mathrm{f}}(\mathrm{n})$ & $83(1-235)$ & $41(11-59)$ & NS \\
\hline Upright acid reflux episodes ${ }^{\mathrm{f}}(\mathrm{n})$ & $61(1-175)$ & $41(10-59)$ & NS \\
\hline Supine acid reflux episodes ${ }^{\mathrm{f}}(\mathrm{n})$ & $9(0-98)$ & $0(0-2)$ & 0.002 \\
\hline DeMeester score $^{\mathrm{f}}$ & $58(0-215)$ & $15(5-43)$ & 0.036 \\
\hline Total acid clearance time ${ }^{\mathrm{f}}(\mathrm{sec})$ & $102(12-264)$ & $96(54-222)$ & NS \\
\hline
\end{tabular}

${ }^{\mathrm{a}}$ After exclusion of 1 patient due to excess swallowing.

${ }^{\mathrm{b}}$ Orally treated diabetes only.

'Grade A or more according to the Los Angeles classification.

${ }^{\mathrm{d}}$ According to Prague criteria. ${ }^{29}$

eThree patients and 4 controls excluded due to catheter discomfort or technical failure.

${ }^{\mathrm{f}}$ Non-normally distributed data.

H. pylori, Helicobacter pylori; NA, not applicable; NS, non-significant.

Data shown as mean $\pm \mathrm{SD}$, median (range), or proportions.

\section{Ambulatory 24-hour esophageal pH and impedance measurement}

Just after the Acid Clearance Test, subjects were asked to participate in an ambulatory $\mathrm{pH}$-impedance measurement using the same catheter. If placed nasally, the catheter was left in place and otherwise relocated to nasal intubation. Following transfer of the clearance test data from the data logger to the computer, a new recording was started and subjects were instructed to record position (upright/supine), meals, and symptoms on the data logger as well 
as in a diary. Besides pausing PPI treatment and refraining from acidic beverages during the measurement, no specific restraints were given. Upon returning the assembly, the catheter was postcalibrated followed by data transfer.

\section{Data analysis}

Data were blinded for raw data analysis. Recordings were checked for quality, and artifacts were excluded from analysis. Meals were excluded from the ambulatory measurement. ACT was analyzed as the time from drop in esophageal $\mathrm{pH}$ below 4 to restoration of $\mathrm{pH}$ above 4 (Fig. 3). ${ }^{7,34}$ Since to our knowledge no previous publications have defined the time frame for which $\mathrm{pH}$ has to be above 4 before acid clearance is considered complete, we based our definition on pilot experiments in healthy controls. Based on these a time period of 15 seconds was chosen, since this gave clearance times similar to previous data. ${ }^{7,34}$ Bolus clearance time (BCT) was analyzed manually and defined as the time from a drop in impedance to below $50 \%$ of the pre-infusion value to restoration above $50 \%$ of the same value for at least 5 seconds. ${ }^{34,39}$ Since volume clearance is defined as the first part of the clearance process and chemical clearance as the second, chemical clearance time (CCT) was calculated as $[\mathrm{CCT}=\mathrm{ACT}-\mathrm{BCT}]$. $^{5}$ The swallowing rate (swallows/min) during the random test was calculated as: [number of random swallows before reaching $\mathrm{pH}$ above 4/random ACT (minutes)].

\section{Statistical Methods}

Statistical analyses were performed using Stata 12 (StataCorp LP, College Station, Texas, USA) and with assistance from the Department of Statistics, Aalborg University Hospital. Normally distributed data are expressed as mean \pm SD and non-normally distributed data as median (range). In Tables 1 and 2, the distribution of the individual parameters including log transformation is indicated. For comparison between groups of continuous data, the Student's $t$ test, mixed effects analysis of variance (ANOVA), or Kruskall-Wallis' rank sum test were used as appropriate. The Holm-Sidak method was used for post-hoc analysis to adjust for multiple comparisons whenever relevant. For comparison of categorical outcome, Fisher's exact test was used. Relevant cofactors as described in the results were analyzed individually to check for possible confounding.

Swallowing rate is known to affect acid clearance. ${ }^{40}$ Therefore, the acid clearance test using random swallowing and those using controlled swallowing were analyzed in separate ANOVAs. Hence, random swallowing rate and clearance times were compared groupwise using one-way ANOVA. In the controlled swallowing tests, clearance times were analyzed as continuous variables using twoway ANOVA with fixed effects parameters being group and the three separate tests (upright, supine, and lozenge).

\section{Results}

\section{Baseline Characteristics and Methodology}

Demography, endoscopy findings, and ambulatory results are presented in Table 1. At baseline, $44 \%$ of patients reported heartburn and $36 \%$ regurgitation at least 1 day/month. A hiatus hernia with an axial length of at least $2 \mathrm{~cm}^{41}$ was present on endoscopy in $76 \%$ of patients and $8 \%$ of controls $(P<0.001)$, and $92 \%$ of patients had long-segment Barrett as defined by at least C0M3. ${ }^{30}$ For the acid clearance test, $40 \%$ of patients with $\mathrm{BE}$ and $42 \%$ of controls were nasally intubated (Table 2). One patient was excluded

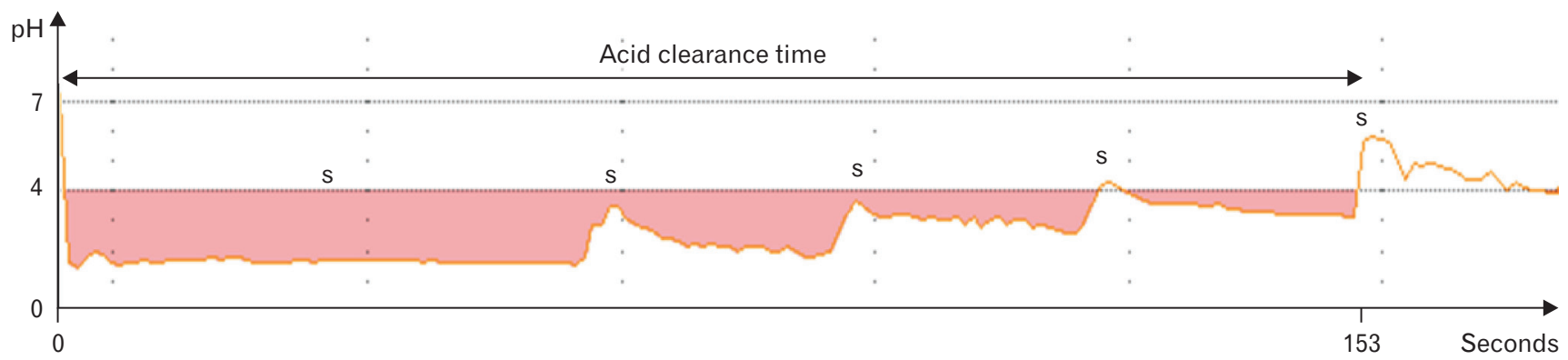

Figure 3. Recording from an upright acid clearance test in a control. The $\mathrm{x}$-axis shows time, the $\mathrm{y}$-axis shows $\mathrm{pH}$ value. The $\mathrm{pH}$ below 4 is indicated by pink color. Acid is instilled at $\mathrm{t}=0$ seconds. Swallows are indicated by "s". The subject is swallowing every 30 seconds and except for the first swallow, each swallow results in a distinct rise in $\mathrm{pH}$. The acid clearance time is measured as the time from acid instillation until $\mathrm{pH}$ is restored above 4 . In this case, 5 swallows or 153 seconds were required for this. 
from the analysis of random ACT due to poor data quality. Another patient was excluded from the whole data set as an outlier because of a swallowing frequency 5 SDs above the mean during the random swallowing test. In total, 5 acid clearance tests in patients and two in controls were censored at 900 seconds. No acid clearance tests had to be stopped because of discomfort, but $18 \%$ of patients with $\mathrm{BE}$ and $50 \%$ of controls refused to undergo or did not tolerate the ambulatory measurement (Table 1). To some degree, low baseline impedance in patients impeded assessment of BCT during the acid clearance test, but still data from $72 \%$ of patients were available for analysis (Table 2). However, data quality and the same low impedance, combined with dropouts from the ambulatory impedance measurement did not allow sufficient analysis of impedance events. Thus, analysis of the post-reflux swallow-induced peristaltic wave index, as has been done in short-segment BE, was not possible. ${ }^{17}$ In fact, some have even suggested refraining from impedance analysis in BE. ${ }^{42}$ During the 24-hour $\mathrm{pH}$ measurement, patients with $\mathrm{BE}$ generally had longer acid exposure time and more acid reflux epi-

Table 2. Results of Acid Clearance Test

\begin{tabular}{|c|c|c|c|c|c|}
\hline & $\begin{array}{c}\text { Barrett } \\
(\mathrm{n}=25)\end{array}$ & $\begin{array}{l}\text { Controls } \\
(\mathrm{n}=12)\end{array}$ & & $\begin{array}{c}\text { Barrett } \\
(\mathrm{n}=25)\end{array}$ & $\begin{array}{l}\text { Controls } \\
(\mathrm{n}=12)\end{array}$ \\
\hline Intubation way & & & Random acid clearance test & & \\
\hline Nasal & $10(40 \%)$ & $5(42 \%)$ & $\mathrm{ACT}^{\mathrm{b}}(\mathrm{sec})$ & $249 \pm 179^{\mathrm{e}, \mathrm{f}}$ & $440 \pm 269^{f}$ \\
\hline Oral & $15(60 \%)$ & $7(58 \%)$ & $\mathrm{BCT}^{\mathrm{b}, \mathrm{c}}(\mathrm{sec})$ & $84 \pm 69$ & $186 \pm 196$ \\
\hline Baseline impedance & & & $\mathrm{CCT}^{\mathrm{b}, \mathrm{c}}(\mathrm{sec})$ & $158 \pm 121$ & $267 \pm 170$ \\
\hline $7 \mathrm{~cm}$ above the LES & $1360 \pm 610$ & $1912 \pm 523$ & Heartburn present (\%) & $5(20 \%)$ & $0(0 \%)$ \\
\hline $5 \mathrm{~cm}$ above the LES & $1089 \pm 472^{\mathrm{e}}$ & $2061 \pm 631$ & Heartburn duration $^{\mathrm{d}}(\mathrm{sec})$ & $0(0-180)$ & $0(0-0)$ \\
\hline $5 \mathrm{~cm}$ above the LES (squamous only ${ }^{\mathrm{a}}$ ) & $1339 \pm 312^{\mathrm{e}}$ & $2061 \pm 631$ & I-score $^{\mathrm{d}}(\mathrm{mm})$ & $0(0-148)$ & $0(0-0)$ \\
\hline $3 \mathrm{~cm}$ above the LES & $931 \pm 495^{\mathrm{e}}$ & $2101 \pm 782$ & No of random swallows during test & $6.8 \pm 5.3$ & $6.5 \pm 4.0$ \\
\hline Saline test & & & Swallowing rate $\left(\min ^{-1}\right)$ & $1.9 \pm 0.7^{\mathrm{e}}$ & $1.2 \pm 0.6$ \\
\hline $\mathrm{BCT}^{\mathrm{b}, \mathrm{c}}(\mathrm{sec})$ & $32 \pm 19$ & $36 \pm 22$ & Lozenge acid clearance test & & \\
\hline Heartburn present & $0(0 \%)$ & $0(0 \%)$ & $\mathrm{ACT}^{\mathrm{b}}(\mathrm{sec})$ & $177 \pm 122^{f}$ & $174 \pm 91^{\mathrm{f}}$ \\
\hline Heartburn duration $^{\mathrm{d}}$ (sec) & $0(0-0)$ & $0(0-0)$ & $\mathrm{BCT}^{\mathrm{b}, \mathrm{c}}(\mathrm{sec})$ & $51 \pm 35$ & $54 \pm 31$ \\
\hline I-score $^{\mathrm{d}}(\mathrm{mm})$ & $0(0-0)$ & $0(0-0)$ & $\mathrm{CCT}^{\mathrm{b}, \mathrm{c}}(\mathrm{sec})$ & $149 \pm 119^{f}$ & $128 \pm 99^{f}$ \\
\hline Random swallows $^{\mathrm{d}}$ & $0(0-1)$ & $0(0-1)$ & Heartburn present (\%) & $3(12 \%)$ & $1(8 \%)$ \\
\hline Upright acid clearance test & & & Heartburn duration $^{\mathrm{d}}$ (sec) & $0(0-240)$ & $0(0-60)$ \\
\hline $\mathrm{ACT}^{\mathrm{b}}(\mathrm{sec})$ & $285 \pm 216$ & 219 (88) & I-score $^{\mathrm{d}}(\mathrm{mm})$ & $0(0-52)$ & $0(0-0)$ \\
\hline $\mathrm{BCT}^{\mathrm{b}, \mathrm{c}}(\mathrm{sec})$ & $64 \pm 42$ & $44(28)$ & Non-planned swallows ${ }^{\mathrm{d}}$ & $0(0-2)$ & $0(0-2)$ \\
\hline $\mathrm{CCT}^{\mathrm{b}, \mathrm{c}}(\mathrm{sec})$ & $144 \pm 121$ & $185(81)$ & All tests in total & & \\
\hline Heartburn present $(\%)$ & 12 & 0 & Heartburn present $(\%)$ & $8(32 \%)$ & $1(8 \%)$ \\
\hline Heartburn duration $^{\mathrm{d}}$ (sec) & $0(0-720)$ & $0(0-0)$ & Heartburn duration $^{\mathrm{d}}$ (sec) & $0(0-720)^{g}$ & $0(0-0)$ \\
\hline I-score $^{\mathrm{d}}(\mathrm{mm})$ & $0(0-60)$ & $0(0-0)$ & I-score $^{\mathrm{d}}(\mathrm{mm})$ & $0(0-314)^{g}$ & $0(0-0)$ \\
\hline Non-planned swallows ${ }^{\mathrm{d}}$ & $0(0-2)$ & $0(0-0)$ & Non-planned swallows, & $0(0-4)$ & $0(0-3)$ \\
\hline Supine acid clearance test & & & controlled trials $^{\mathrm{d}}(\mathrm{n})$ & & \\
\hline $\mathrm{ACT}^{\mathrm{b}}(\mathrm{sec})$ & $412 \pm 269^{f}$ & $336 \pm 185^{\mathrm{f}}$ & & & \\
\hline $\mathrm{BCT}^{\mathrm{b}, \mathrm{c}}(\mathrm{sec})$ & $105 \pm 151^{\mathrm{f}}$ & $78 \pm 54^{f}$ & & & \\
\hline $\mathrm{CCT}^{\mathrm{b}, \mathrm{c}}(\mathrm{sec})$ & $265 \pm 218^{\mathrm{f}}$ & $279 \pm 168^{f}$ & & & \\
\hline Heartburn present $(\%)$ & $4(16 \%)$ & $1(8 \%)$ & & & \\
\hline Heartburn duration $^{\mathrm{d}}$ (sec) & $0(0-180)$ & $0(0-0)$ & & & \\
\hline I-score $^{\mathrm{d}}(\mathrm{mm})$ & $0(0-166)$ & $0(0-0)$ & & & \\
\hline Non-planned swallows ${ }^{\mathrm{d}}$ & $0(0-3)$ & $0(0-1)$ & & & \\
\hline
\end{tabular}

${ }^{a}$ Excluding patients with a Barrett segment reaching the electrodes, thus analyzing squamous epithelium data only.

${ }^{\mathrm{b}}$ Data were $\log (\ln )$ transformed for the statistical analysis, but mean and SD shown here are based on raw data.

'Data quality only allowed measurement of BCT (and thus calculation of CCT) for 18 patients (72\%) and 11 controls (92\%).

${ }^{\mathrm{d}}$ Non-normally distributed data.

${ }^{\mathrm{e}} \mathrm{P}<0.01$ vs controls.

${ }^{\mathrm{f}} P<0.05$ vs upright trial when considering both groups.

${ }^{\mathrm{g}} \mathrm{P}<0.05$ vs controls.

LES, lower esophageal sphincter; BCT, bolus clearance time; ACT, acid clearance time; CCT, chemical clearance time; I-score, intensity score of heartburn.

Data shown as mean $\pm \mathrm{SD}$, median (range), or proportions depending on distribution. 
sodes (Table 1).

Analysis of the cofactors age, sex, BMI, smoking status, and diabetes for possible confounding showed no indication of this. For intubation way and $\mathrm{EE}$ presence, some analyses indicated possible confounding. Tentative exclusion of subjects with the highest BMI and age was also performed, thus achieving similar values in the 2 groups. However, neither the performed tentative exclusions nor the adjustment for intubation way and EE presence in the models changed the significance of results. In general as well as in Table 2, unadjusted results and significance are reported.

\section{Barrett's Esophagus Patients Cleared Acid Faster Due to More Frequent Swallowing}

Figure 4 and Table 2 show acid clearance test data. Distal esophageal baseline impedance was lower in patients, even when only considering data from squamous epithelium (Table 2). When swallowing randomly, patients swallowed $60 \%$ more often (mean swallowing rate $1.9 \pm 0.7$ vs $1.2 \pm 0.6$ swallows $/ \mathrm{min}, P=0.004$; Fig. 4A) and had a $46 \%$ shorter ACT than controls $(P=0.008$, Fig. 4B). Furthermore, a shorter ACT was correlated with a higher swallowing rate when swallowing randomly $(P<0.001$, Fig. 4C). When removing the possibility to swallow at will by controlling the swallowing rate however, no differences in clearance times between patients and controls were observed (Table 2). The total duration of heartburn was longer and the scored intensity was stronger in patients than in controls during the acid clearance test (Table 2).

Neither acid clearance time nor acid exposure recorded during the ambulatory $\mathrm{pH}$-impedance measurement could confirm the re- sults of the standardized acid clearance test. Both of these ambulatory parameters showed no correlation with any of the experimental tests (all $P>0.3$ ).

Patients with $\mathrm{BE}$ with concomitant $\mathrm{EE}$ showed a trend to a $64 \%$ longer ACT during random swallowing than patients without $\mathrm{EE}(P=0.073)$. Accordingly, tentative exclusion of patients with $\mathrm{BE}$ also having $\mathrm{EE}(\mathrm{n}=8)$ only strengthened the findings, since patients with $\mathrm{BE}$ then showed a $54 \%$ shorter acid clearance time than controls $(P=0.003)$. As for the controlled swallowing tests, similar stratified analysis and tentative exclusion showed practically no effect of EE presence on acid clearance times (all $P>0.3$, detailed data not shown). When considering all subjects (patients with $\mathrm{BE}$ and controls), ACT during random swallowing was $49 \%$ shorter in subjects with an $\mathrm{HH}$ than in those without $(P=0.001)$.

\section{Associations Between Swallowing Rate, Baseline Impedance, and Acid Exposure}

A higher swallowing rate was associated with a lower distal esophageal baseline impedance when analyzing all subjects $(P=$ 0.014, Fig. 5A). Furthermore, maximal Barrett segment length in patients increased with lower baseline impedance $(P=0.004$, Fig. $5 \mathrm{~B})$. The correlation between swallowing rate and esophageal baseline impedance was still present when tentatively excluding patients with columnar epithelium at the site of impedance measurement as explained in the legend for Figure $5(P=0.007)$. No correlation was present between baseline impedance and $\mathrm{ACT}($ all $P>0.3)$.
A

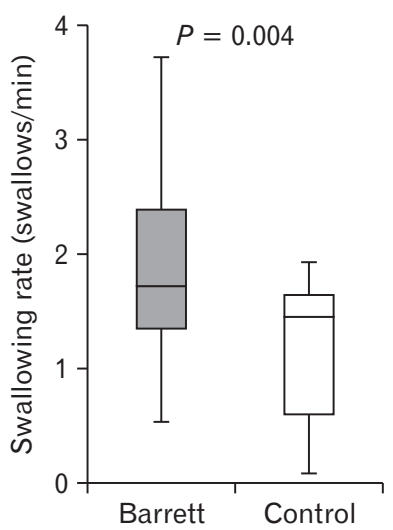

B

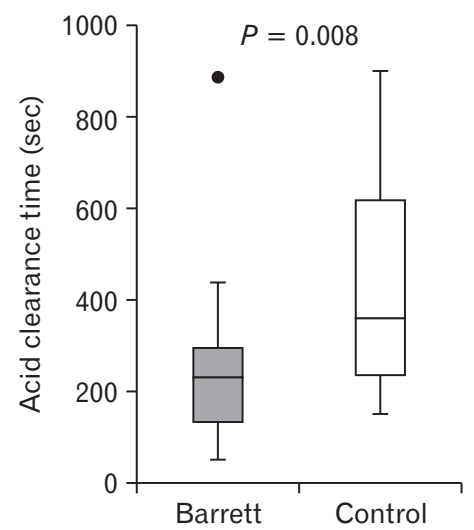

C

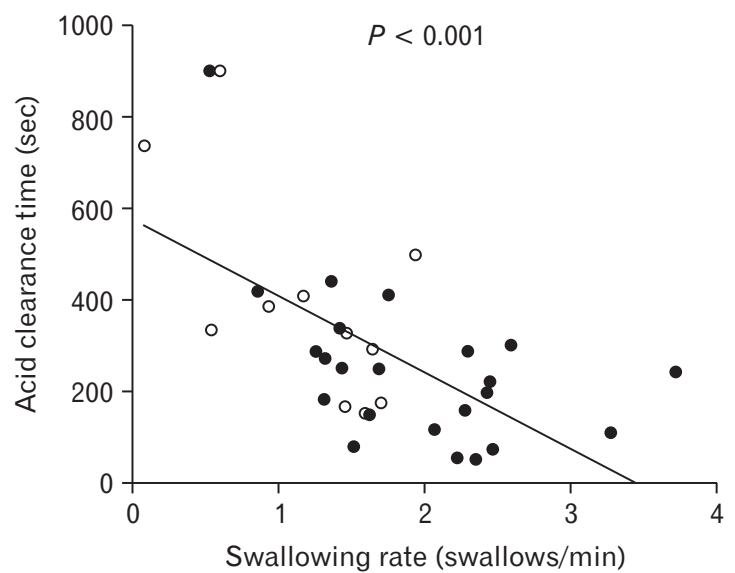

Figure 4. Swallowing rate and acid clearance time measured during the random swallowing trial. Compared with controls, patients with Barrett's esophagus swallowed more frequently (A) and had faster acid clearance (B). Furthermore, these 2 parameters were inversely correlated (C). In the correlation, closed circles indicate patients with Barrett's esophagus and open circles controls. 

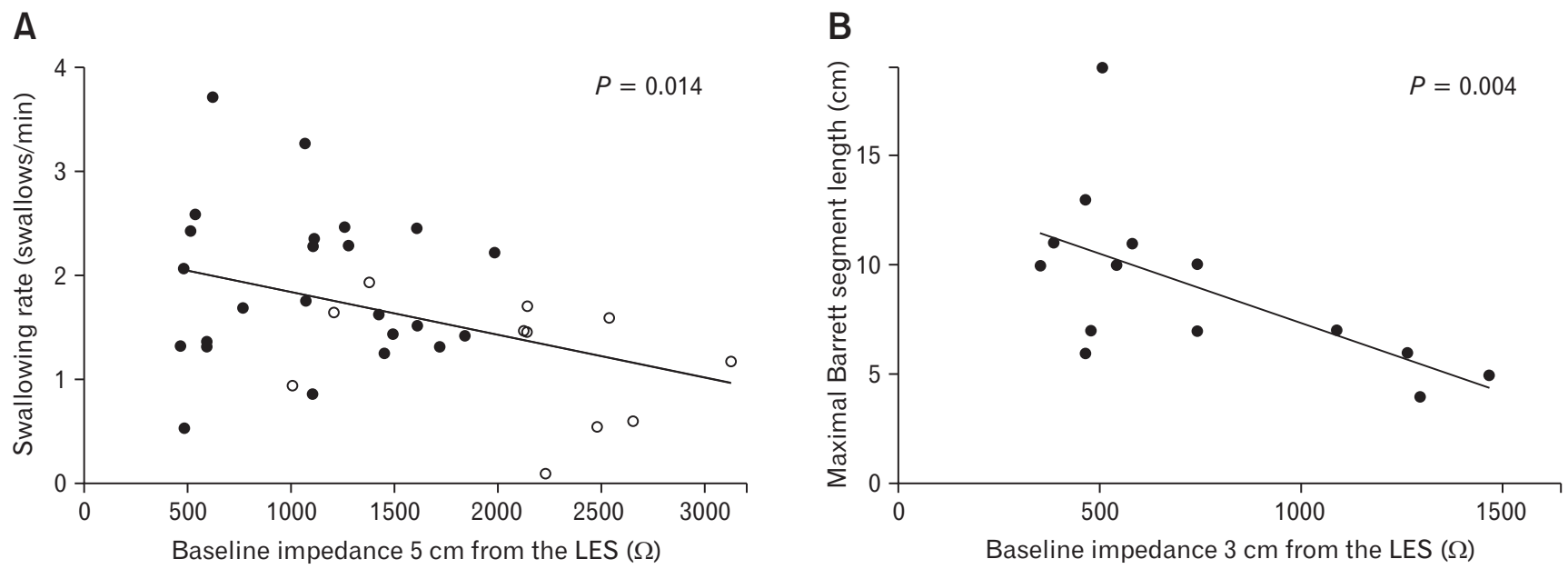

Figure 5. Associations between mucosal baseline impedance, swallowing rate, and Barrett segment length. Swallowing rate (A) and Barrett segment length (B) both increased with lower baseline impedance. In (A), tentatively excluding patients with columnar epithelium at $5 \mathrm{~cm}$ above the lower esophageal sphincter (LES), thus performing the analysis based on only data from squamous epithelium, did not change significance $(P=$ 0.007). In (B), only data from columnar epithelium are shown. The number of subjects with data from only squamous epithelium at this measuring site did not allow analysis. In (A), closed circles indicate patients with Barrett's esophagus and open circles controls.

\section{Discussion}

To identify acid clearance mechanisms in BE we used the standardized esophageal acid clearance test and ambulatory $\mathrm{pH}$ impedance testing. During random swallowing, patients swallowed $60 \%$ more often than controls resulting in a $46 \%$ shorter acid clearance. However, ambulatory acid exposure was still increased. The greater swallowing rate may thus be interpreted as an insufficient anti-reflux mechanism. In line with this, no association was observed between acid clearance using the standardized test and that using ambulatory $\mathrm{pH}$.

The only published study we are aware of in a BE population using the acid clearance test supports our findings: with comparable conditions including random swallowing, Orr et $\mathrm{al}^{25}$ found faster acid clearance and shorter swallow latency in patients with $\mathrm{BE}$ than in controls. To our knowledge however, we are the first to show an increased swallowing rate in patients with $\mathrm{BE}$ and its correlation with shorter acid clearance time. In our control subjects, supine as well as upright acid clearance times were in line with other studies using the acid clearance test ${ }^{34,37}$ and random swallowing rate also similar to that previously reported. ${ }^{43,44}$

Contrary to our findings in patients with $\mathrm{BE}$, others have found prolonged acid clearance using controlled swallowing in the acid clearance test. However, these findings were based on a total of only16 patients with $\mathrm{BE}$. All of these patients had either EE, previous surgery, strictures, or other complications along with $\mathrm{BE} .^{22,27}$
Moreover, 2 studies ${ }^{45,46}$ showed similar and 1 even better motility in $\mathrm{BE}$ compared with patients with EE. ${ }^{47}$ The latter finding specifically supports our own results, although insignificant, showing a $64 \%$ longer acid clearance time in patients with $\mathrm{BE}$ and $\mathrm{EE}$ than in $\mathrm{BE}$ without $\mathrm{EE}$.

In relation to ambulatory $\mathrm{pH}$ measurements, a number of studies confirm our findings of greater acid exposure in patients with BE compared with controls. ${ }^{15,47-49}$ Only one ambulatory study showed prolonged acid clearance time in BE. However, their controls were 12 and 17 years younger than patients which could possibly have confounded the results. ${ }^{3,50}$ A positive correlation between acid clearance times obtained with the acid clearance test and ambulatory monitoring, which we could not show, has been shown by only 2 studies, ${ }^{21,51}$ neither demonstrating this relation in patients with $\mathrm{BE}$. As for our results indicating that $\mathrm{HH}$ presence shortens acid clearance, previous studies have shown prolonged acid clearance in $\mathrm{HH}$ patients. ${ }^{23,24}$ However, these studies included $\mathrm{HH}$ patients without $\mathrm{BE}$ and therefore cannot be used for comparison.

As for the selection process, previous data did not allow a true sample size calculation and thus sample size was chosen based on experience. Despite the objective criteria used, bias in the selection process cannot be ruled out, eg, the included patients may not be representative of the whole patient population. Except for one missing control, the groups were equal to the preselected sample size. However, this sample size was somewhat reduced by dropouts, possibly due to the extensive protocol including 2 visits and multiple 
intubations.

In relation to demographic cofactors, some heterogeneity within groups is inevitable. Considering whether the investigated $\mathrm{BE}$ population is representative overall, also taking into account sample size, other largely similar studies have included widely comparable populations. ${ }^{25,52-55}$ Yet, the older age and higher BMI in patients compared with controls in the present study and patient heterogeneity such as eg, presence of $\mathrm{EE}$ could pose a problem. However, specific analyses on these subjects to detect possible confounding did not change results. Furthermore, neither tentative exclusion of patients with $\mathrm{EE}$, higher $\mathrm{BMI}$, nor older age changed results. The same was true when subjects intubated orally were excluded. Furthermore, esophageal function decreases with age ${ }^{56}$ and greater BMI is associated with more severe reflux. ${ }^{1}$ Thus if these factors should have affected the results, the differences shown between groups would only have been reduced.

Conclusively, we find little reason to assume that our findings including increased swallowing and shorter acid clearance in patients are due to confounding. However, considering the limitations present, the results will need verification in future studies. In terms of external validity, our findings can only solidly be generalized to patients with BE.

In regard to the protocol, the oral intubation in some subjects might affect the results due to an effect on salivation. ${ }^{57}$ However, a similar proportion in both groups was intubated either way. Furthermore, the results were unaffected when adjusting for intubation way as a cofactor as well as when tentatively excluding subjects intubated orally. Rebound acid hypersecretion due to the PPI break is possible, but most likely not important within the 4-day break used. ${ }^{58,59}$ We believe that blinding of subjects to the test liquid used should assure unbiased results in terms of, eg, swallowing rate and heartburn. As a result of our chosen protocol, the random swallowing test was only performed in the upright position. However, others have shown similar findings in the supine position. ${ }^{25}$ Esophageal manometry could have characterized motility parameters and swallowing better, but unfortunately was inaccessible. Ambulatory $\mathrm{pH}$-impedance measurement is another option to assess esophageal acid clearance, which in reality however only measures acid and bolus exposure times and not the volume of the acid bolus being cleared. ${ }^{19,60}$ Due to the high prevalence of $\mathrm{HH}$ in $\mathrm{BE}^{61}$ and common large-volume as well as repeated reflux episodes (re-reflux) in $\mathrm{HH}$ patients, ${ }^{24}$ ambulatory clearance times may be artifactually prolonged. ${ }^{18,62}$ Thus, an ambulatory $\mathrm{pH}$ measurement showing increased acid exposure in $\mathrm{BE}$ cannot per se be considered evidence that esophageal acid clearance function is impaired. It may merely represent repeated and/or large-volume reflux episodes.

As opposed to the ambulatory measurement, the acid clearance test uses standardized reflux volume and acidity, thus minimizing possible confounding. ${ }^{18}$ This difference probably explains the lack of association between the clearance times in the ambulatory measurement and those in the acid clearance test. However, a type 2 error is also possible. Although experimental, we believe the acid clearance test has clinical relevance as a physiological assessment. Previous findings show that most reflux episodes in patients with $\mathrm{BE}$ do reach a height corresponding to the acid infusion channel 15 $\mathrm{cm}$ above the LES in our setup. ${ }^{3}$ Furthermore, we demonstrated a correlation between the objective parameter of baseline impedance and the somewhat subjective swallowing rate. This indicates a pathophysiological base for the findings. No previous data exist to contradict our finding of increased swallowing rates in patients with $\mathrm{BE}$, on the contrary, one previous study came to a similar conclusion. ${ }^{25}$ Future studies should reproduce our findings with other methods such as catheter-based ambulatory manometry. However, the swallowing rate thus measured could be biased, since the higher acid exposure in patients with $\mathrm{BE}$ in the clinical setting would theoretically also increase swallowing rates to a greater extent than in controls. $^{44}$

We found that patients with BE had lower distal esophageal baseline impedance, which correlated with a greater swallowing rate. This was also true when only data from controls and squamous mucosa in patients with BE were included. Previous studies have linked low esophageal baseline impedance and impaired mucosal integrity to heartburn and acid hypersensitivity. ${ }^{63,64}$ Accordingly, one previous study using controls for comparison also found indications of hypersensitivity to acid infusion in $\mathrm{BE}{ }^{55}$ Opposed to this, 3 studies demonstrated hyposensitivity to acid perfusion in $\mathrm{BE}$, all however using patients with $\mathrm{EE}$ as the control group. ${ }^{52,54,65}$ Since patients with EE show sensitization and more mucosal inflammation than $\mathrm{BE},{ }^{66,67}$ hypersensitivity in $\mathrm{EE}$ relative to $\mathrm{BE}$ could likely explain the relative acid hyposensitivity in BE reported in these studies. ${ }^{52,54,65}$ In this regard, our finding of more severe heartburn in patients with $\mathrm{BE}$ during the acid clearance test could indicate acid hypersensitivity. We believe that the lower baseline impedance indicates impaired mucosal integrity, which would allow faster ion (ie, acid) transfer across the cell membrane to reach acid receptors. ${ }^{68}$ The resulting acid hypersensitivity could possibly explain the increased swallowing rate and faster acid clearance in patients with BE.

The paradoxical findings of concurrent longer ambulatory acid exposure time in patients with $\mathrm{BE}$ despite shorter acid clearance 
time during the random acid clearance test need an explanation. Factors such as esophagogastric junction incompetence, presence of $\mathrm{HH}$, and large-volume nightly reflux all increase the amount of gastroesophageal reflux, ${ }^{1,25,61}$ most likely also in our patients with $\mathrm{BE}$. We believe the increased swallowing rate is a physiologic compensatory mechanism to resist this reflux. However, since acid exposure in BE is still greater, the compensation seems to be insufficient, which could explain the above mentioned paradox. A clinical solution to the massive reflux that appears to be the problem could be anti-reflux surgery, which has been shown to prevent progression in $\mathrm{BE}^{69}$ Alongside that, standard medical treatment remains to be PPI guided by symptoms. ${ }^{1}$

Conclusively, we have proposed novel esophageal pathophysiology in BE such as more frequent swallowing and the association of this parameter to lower baseline impedance. In future research, it seems essential to confirm these findings and to gain further insight into the exact underlying sensory-mechanical interactions. The ambulatory $\mathrm{pH}$-impedance measurement remains the state-of-the-art method for assessing the magnitude of reflux in gastroesophageal reflux disease including Barrett's esophagus. ${ }^{70}$ However, our results suggest that this measurement in patients with $\mathrm{BE}$ will not always accurately represent esophageal clearance function. We propose that the greater acid exposure in BE may not be explained by an impaired acid clearance as such, but rather by a greater amount of reflux. Acid-evoked, protective reflexes seem to facilitate more frequent swallowing in an inadequate attempt to clear the refluxed acid. Despite this, increased volume and frequency of reflux episodes appear to tip the balance over time, leading to reflux-induced changes in the epithelium.

Financial support: Christian Lottrup was partially supported by The Danish Medical Association Research Fund, The Heinrich Kopp Fund, The Hertha Christensen Fund, The Frimodt Fund, The King Christian X Fund, The PA Andersen and Wife Fund, and The Director Jacob Madsen and Wife Olga Madsen Fund. Hans Gregersen was partially supported by grants from Chongqing Science and Technology Commission (No. cstc2013kjrcljrccj10003) and National "111 Plan” Base (No. B06023).

\section{Conflicts of interest: None.}

Author contributions: Christian Lottrup performed the acid clearance experiments, analyzed the raw data, performed statistical analyses, interpreted the data, drafted the manuscript, and prepared the manuscript for submission; Anne L Krarup, Asbjørn M
Drewes, and Hans Gregersen interpreted the data and reviewed the manuscript; and Per Ejstrud performed the endoscopies and reviewed the manuscript. All authors participated in the planning of the study and approved the final manuscript for submission.

\section{References}

1. Shaheen NJ, Richter JE. Barrett's oesophagus. Lancet 2009;373:850861

2. Inadomi JM. Cost considerations in implementing a screening and surveillance strategy for Barrett's oesophagus. Best Pract Res Clin Gastroenterol 2015;29:51-63.

3. Savarino E, Zentilin P, Frazzoni M, et al. Characteristics of gastroesophageal reflux episodes in Barrett's esophagus, erosive esophagitis and healthy volunteers. Neurogastroenterol Motil 2010;22:1061-e280.

4. Byrne PJ, Mulligan ED, O'Riordan J, Keeling PWN, Reynolds J V. Impaired visceral sensitivity to acid reflux in patients with Barrett's esophagus. The role of esophageal motility*. Dis Esophagus 2003;16:199-203.

5. Helm JF. Esophageal acid clearance. J Clin Gastroenterol 1986;8(suppl 1):5-11.

6. Anggiansah A, Taylor G, Bright N, et al. Primary peristalsis is the major acid clearance mechanism in reflux patients. Gut 1994;35:1536-1542.

7. Helm JF, Dodds WJ, Pelc LR, Palmer DW, Hogan WJ, Teeter BC. Effect of esophageal emptying and saliva on clearance of acid from the esophagus. N Engl J Med 1984;310:284-288.

8. Namiot Z, Rourk RM, Piascik R, Hetzel DP, Sarosiek J, McCallum RW. Interrelationship between esophageal challenge with mechanical and chemical stimuli and salivary protective mechanisms. Am J Gastroenterol 1994;89:581-587.

9. Schoeman M, Holloway R. Integrity and characteristics of secondary oesophageal peristalsis in patients with gastro-oesophageal reflux disease. Gut 1995;36:499-504.

10. Kavanagh ME, O'Sullivan KE, O'Hanlon C, O'Sullivan JN, Lysaght J, Reynolds J V. The esophagitis to adenocarcinoma sequence; the role of inflammation. Cancer Lett 2014;345:182-189.

11. Kapoor H, Agrawal DK, Mittal SK. Barrett's Esophagus: Recent insights into pathogenesis and cellular ontogeny. Transl Res 2015;166:2840

12. Trimble KC, Pryde A, Heading RC. Lowered oesophageal sensory thresholds in patients with symptomatic but not excess gastro-oesophageal reflux: evidence for a spectrum of visceral sensitivity in GORD. Gut $1995 ; 37: 7-12$.

13. Krarup AL, Olesen SS, Funch-Jensen P, Gregersen H, Drewes AM. Proximal and distal esophageal sensitivity is decreased in patients with Barrett's esophagus. World J Gastroenterol 2011;17:514-521.

14. Martinucci I, de Bortoli N, Giacchino M et al. Esophageal motility abnormalities in gastroesophageal reflux disease. World J Gastrointest Pharmacol Ther 2014;5:86-96.

15. Gutschow CA, Bludau M, Vallböhmer D, Schröder W, Bollschweiler E, Hölscher AH. NERD, GERD, and Barrett's esophagus: role of acid and non-acid reflux revisited with combined $\mathrm{pH}$-impedance monitoring. 
Dig Dis Sci 2008;53:3076-3081.

16. Stein HJ, Hoeft S, DeMeester TR. Functional foregut abnormalities in Barrett's esophagus. J Thorac Cardiovasc Surg 1993;105:107-111.

17. Frazzoni M, Bertani H, Conigliaro R, Frazzoni L, Losi L, Melotti G. Neoplastic progression in short-segment Barrett's oesophagus is associated with impairment of chemical clearance, but not inadequate acid suppression by proton pump inhibitor therapy. Aliment Pharmacol Ther 2014;40:835-842.

18. Vicente Y, da Rocha C, Hernandez-peredo G, Madero R, Tovar JA. Esophageal Acid clearance : more volume-dependent than motilitydependent in healthy piglets. J Pediatr Gastroenterol Nutr 2002;35:173179.

19. Shay SS, Johnson LF, Richter JE. Acid rereflux: a review, emphasizing detection by impedance, manometry, and scintigraphy, and the impact on acid clearing pathophysiology as well as interpreting the $\mathrm{pH}$ record. Dig Dis Sci 2003;48:1-9.

20. Booth DJ, Kemmerer WT, Skinner DB. Acid clearing from the distal esophagus. Arch Surg 1968;96:731-734.

21. Stanciu C, Bennett JR. Oesophageal acid clearing: one factor in the production of reflux oesophagitis. Gut 1974;15:852-857.

22. Singh P, Taylor RH, Colin-Jones DG. Esophageal motor dysfunction and acid exposure in reflux esophagitis are more severe if Barrett's metaplasia is present. Am J Gastroenterol 1994;89:349-356.

23. Sloan S, Kahrilas PJ. Impairment of esophageal emptying with hiatal hernia. Gastroenterology 1991;100:596-605.

24. Mittal RK, Lange RC, McCallum RW. Identification and mechanism of delayed esophageal acid clearance in subjects with hiatus hernia. Gastroenterology 1987;92:130-135.

25. Orr WC, Lackey C, Robinson MG, Johnson LF, Welsh JD. Esophageal acid clearance during sleep in patients with Barrett's esophagus. Dig Dis Sci 1988;33:654-659.

26. Singh P, Adamopoulos A, Taylor RH, Colin-Jones DG. Oesophageal motor function before and after healing of oesophagitis. Gut 1992;33:1590-1596.

27. Iascone C, DeMeester TR, Little AG, Skinner DB. Barrett's esophagus. Functional assessment, proposed pathogenesis, and surgical therapy. Arch Surg 1983;118:543-549.

28. Lottrup C, McMahon BP, Ejstrud P, Ostapiuk MA, Funch-Jensen P, Drewes AM. Esophagogastric junction distensibility in hiatus hernia. Dis Esophagus 2016;29:463-471.

29. Shaheen NJ, Falk GW, Iyer PG, Gerson L. ACG clinical guideline: diagnosis and management of Barrett's esophagus. Am J Gastroenterol 2016;111:30-50..

30. Sharma P, Dent J, Armstrong D, et al. The development and validation of an endoscopic grading system for Barrett's esophagus: the Prague C \& M criteria. Gastroenterology 2006;131:1392-1399.

31. Ronkainen J, Aro P, Storskrubb T, et al. Prevalence of Barrett's esophagus in the general population: an endoscopic study. Gastroenterology 2005;129:1825-1831.

32. Chey WD, Woods M, Scheiman JM, Nostrant TT, DelValle J. Lansoprazole and ranitidine affect the accuracy of the ${ }^{14} \mathrm{C}$-urea breath test by a pH-dependent mechanism. Am J Gastroenterol 1997;92:446-450.
33. Hsu WH, Wang SS, Kuo CH, et al. Dual specimens increase the diagnostic accuracy and reduce the reaction duration of rapid urease test. World J Gastroenterol 2010;16:2926-2930.

34. Simrén M, Silny J, Holloway R, Tack J, Janssens J, Sifrim D. Relevance of ineffective oesophageal motility during oesophageal acid clearance. Gut 2003;52:784-790.

35. Hemmink GJ, Weusten BL, Oors J, Bredenoord AJ, Timmer R, Smout AJ. Ambulatory oesophageal $\mathrm{pH}$ monitoring: a comparison between antimony, ISFET, and glass $\mathrm{pH}$ electrodes. Eur J Gastroenterol Hepatol 2010;22:572-577.

36. Lacy BE, O'Shana T, Hynes M, et al. Safety and tolerability of transoral Bravo capsule placement after transnasal manometry using a validated conversion factor. Am J Gastroenterol 2007;102:24-32.

37. Helm JF, Dodds WJ, Riedel DR, Teeter BC, Hogan WJ, Arndorfer RC. Determinants of esophageal acid clearance in normal subjects. Gastroenterology 1983;85:607-612.

38. Krarup AL, Villadsen GE, Mejlgaard E, Olesen SS, Drewes AM, Funch-Jensen P. Acid hypersensitivity in patients with eosinophilic oesophagitis. Scand J Gastroenterol 2010;45:273-281.

39. Park EJ, Lee JS, Lee TH, et al. High-resolution impedance manometry criteria in the sitting position indicative of incomplete bolus clearance. $\mathrm{J}$ Neurogastroenterol Motil 2014;20:491-496.

40. Shaker R, Kahrilas PJ, Dodds WJ, Hogan WJ. Oesophageal clearance of small amounts of equal or less than one millilitre of acid. Gut 1992;33:7-10.

41. Kahrilas PJ, Kim HC, Pandolfino JE. Approaches to the diagnosis and grading of hiatal hernia. Best Pract Res Clin Gastroenterol 2008;22:601616.

42. Hemmink G, Alvarez Herrero L, Bogte A, et al. Esophageal motility and impedance characteristics in patients with Barrett's esophagus before and after radiofrequency ablation. Eur J Gastroenterol Hepatol 2013;25:1029:1032.

43. Orr WC, Johnson LF, Robinson MG. Effect of sleep on swallowing, esophageal peristalsis, and acid clearance. Gastroenterology 1984;86:814819

44. Dent J, Dodds WJ, Friedman RH, et al. Mechanism of gastroesophageal reflux in recumbent asymptomatic human subjects. J Clin Invest 1980;65:256-267.

45. Savarino E, Gemignani L, Pohl D, et al. Oesophageal motility and bolus transit abnormalities increase in parallel with the severity of gastrooesophageal reflux disease. Aliment Pharmacol Ther 2011;34:476-486.

46. Coenraad M, Masclee AA, Straathof JW, Ganesh S, Griffioen G, Lamers CB. Is Barrett's esophagus characterized by more pronounced acid reflux than severe esophagitis? Am J Gastroenterol 1998;93:1068-1072.

47. Parrilla P, Ortiz a, Martinez de Haro LF, Aguayo JL, Ramirez P. Evaluation of the magnitude of gastro-oesophageal reflux in Barrett's oesophagus. Gut 1990;31:964-967.

48. Salminen JT, Tuominen JA, Rämö OJ, Färkkilä MA, Salo JA. Oesophageal acid exposure : higher in Barrett's oesophagus than in reflux oesophagitis. Ann Med 1999;31:46-50.

49. Fiorucci S, Santucci L, Farroni F, Pelli MA, Morelli A. Effect of omeprazole on gastroesophageal reflux in Barrett's esophagus. Am J 
Gastroenterol 1989;84:1263-1267.

50. Hallan A, Bomme M, Hveem K, Møller-Hansen J, Ness-Jensen E. Risk factors on the development of new-onset gastroesophageal reflux symptoms. A population-based prospective cohort study: the HUNT study. Am J Gastroenterol 2015;110:393-400.

51. Basilisco G, Barbera R, Molgora M, Vanoli M, Bianchi P. Acid clearance and oesophageal sensitivity in patients with progressive systemic sclerosis. Gut 1993;34:1487-1491.

52. Johnson DA, Winters C, Spurling TJ, Chobanian SJ, Cattau EL Jr. Esophageal acid sensitivity in Barrett's esophagus. J Clin Gastroenterol 1987;9:23-27.

53. Smythe A, Elghellal K, Kelty C, Mitton D, Patel K, Ackroyd R. The effect of argon plasma coagulation ablation on esophageal motility and chemoreceptor sensitivity in Barrett's esophagus patients. Dis Esophagus 2010;23:445-450.

54. Fass R, Yalam JM, Camargo L, Johnson C, Garewal HS, Sampliner RE. Increased esophageal chemoreceptor sensitivity to acid in patients after successful reversal of Barrett's esophagus. Dig Dis Sci 1997;42:18531858.

55. Fletcher J, Gillen D, Wirz A, McColl KE. Barrett's esophagus evokes a quantitatively and qualitatively altered response to both acid and hypertonic solutions. Am J Gastroenterol 2003;98:1480-1486.

56. Rao SS, Mudipalli RS, Mujica VR, Patel RS, Zimmerman B. Effects of gender and age on esophageal biomechanical properties and sensation. Am J Gastroenterol 2003;98:1688-1695.

57. Kapila YV, Dodds WJ, Helm JF, Hogan WJ. Relationship between swallow rate and salivary flow. Dig Dis Sci 1984;29:528-533.

58. Hunfeld NG, Geus WP, Kuipers EJ. Systematic review: rebound acid hypersecretion after therapy with proton pump inhibitors. Aliment Pharmacol Ther 2007;25:39-46.

59. Reimer C, Søndergaard B, Hilsted L, Bytzer P. Proton-pump inhibitor therapy induces acid-related symptoms in healthy volunteers after withdrawal of therapy. Gastroenterology 2009;137:80-87, e1.

60. Altomare A, Guarino MP, Emerenziani S, et al. Gastrointestinal sensitivi- ty and gastroesophageal reflux disease. Ann N Y Acad Sci 2013;1300:8095.

61. Cameron AJ. Barrett's esophagus: prevalence and size of hiatal hernia. Am J Gastroenterol 1999;94:2054-2059.

62. Holloway RH. Esophageal body motor response to reflux events: secondary peristalsis. Am J Med 2000;108(suppl 4a):20S-26S.

63. Woodland P, Al-Zinaty M, Yazaki E, Sifrim D. In vivo evaluation of acid-induced changes in oesophageal mucosa integrity and sensitivity in non-erosive reflux disease. Gut 2013;62:1256-1261.

64. Zhong C, Duan L, Wang K, et al. Esophageal intraluminal baseline impedance is associated with severity of acid reflux and epithelial structural abnormalities in patients with gastroesophageal reflux disease. J Gastroenterol 2013;48:601-610.

65. Murphy PP, Johnston BT, Collins JSA. Mucosal sensitivity and salivary response to infused acid in patients with columnar-lined oesophagus. Eur J Gastroenterol Hepatol 1994;6:901-906.

66. Fitzgerald RC, Onwuegbusi BA, Bajaj-Elliott M, Saeed IT, Burnham WR, Farthing MJ. Diversity in the oesophageal phenotypic response to gastro-oesophageal reflux: immunological determinants. Gut 2002;50:451-459.

67. Fass R, Naliboff B, Higa L, et al. Differential effect of long-term esophageal acid exposure on mechanosensitivity and chemosensitivity in humans. Gastroenterology 1998;115:1363-1373.

68. Weijenborg PW, Smout AJ, Verseijden C, et al. Hypersensitivity to acid is associated with impaired esophageal mucosal integrity in patients with gastroesophageal reflux disease with and without esophagitis. Am J Physiol Gastrointest Liver Physiol 2014;307:G323-G329.

69. Chang EY, Morris CD, Seltman AK, et al. The effect of antireflux surgery on esophageal carcinogenesis in patients with barrett esophagus: a systematic review. Ann Surg 2007;246:11-21.

70. Kahrilas PJ, Shaheen NJ, Vaezi MF. American Gastroenterological Association Institute technical review on the management of gastroesophageal reflux disease. Gastroenterology 2008;135:1392-1413, e5. 